\title{
Development of Fundamental Data on Chemical Speciation and Solubility for Strontium and Americium in High-Level Waste: Predictive Modeling of Phase Partitioning During Tank Processing
}

(Project Number: 73749)

\section{Principal Investigators}

\author{
Dr. Andrew R. Felmy \\ Pacific Northwest National Laboratory \\ P.O. Box 999, MSIN K8-96 \\ Richland, WA 99352 \\ 509-376-4079 (phone) \\ 509-376-3650 (fax) \\ ar.felmy@pnl.gov \\ Dr. Gregory Choppin \\ The Florida State University \\ Department of Chemistry, B-164 \\ Tallahassee, FL 32606-3006 \\ 904-644-3875 (phone) \\ 904-644-8281 (fax) \\ Choppin@chemmail.chem.fsu.edu
}

Dr. David A. Dixon

Pacific Northwest National Laboratory

P.O. Box 999, MSIN K1-83

Richland, WA 99352

509-372-4999 (phone)

509-375-6631 (fax)

da.dixon@pnl.gov 


\section{Research Objective}

In this project, Pacific Northwest National Laboratory (PNNL) and Florida State University (FSU) are investigating the speciation of $\mathrm{Sr}$ and $\mathrm{Am} / \mathrm{Cm}$ in the presence of selected organic chelating agents over ranges of hydroxide, carbonate, ionic strength, and competing metal ion concentrations present in high-level waste (HLW) stored in tanks at Hanford and other U.S. Department of Energy (DOE) sites. The chelating agents that are being studied are EDTA (ethylenediaminetetraacetic acid), HEDTA (N-(2-hydroxyethyl)ethylenediaminetriacetic acid), NTA (nitrilotriacetic acid), IDA (iminodiacetic acid), citrate, and oxalate.

The project comprises integrated research tasks that approach the problem of chemical speciation using macroscopic thermodynamic measurements of metal-ligand competition reactions, molecular modeling studies to identify structures or complexes of unusual stability, and mass spectrometry measurements of complex charge/mass ratio that can be applied to mixed metalchelate systems. This fundamental information then is used to develop thermodynamic models designed to predict changes in chemical speciation and solubility resulting from various tankprocessing conditions. In this way we can develop new approaches that address fundamental problems in aqueous speciation and, at the same time, provide useful and practical information needed for tank waste processing.

Current strategies for reducing the total volume of radioactive tank waste requiring disposal at Hanford and other DOE sites call for the development of methods that can be used to selectively dissolve and remove non-radioactive elements, such as $\mathrm{Al}, \mathrm{P}$, and $\mathrm{Cr}$, while retaining or precipitating the radioactive elements, including $\mathrm{Sr}$ and the actinide elements, in the tank sludge. This partitioning between solids and precipitates is fundamentally dependent on the chemical speciation of the elements present in the tank processing solutions. Of particular importance is separation of the radioactive and hazardous actinide elements and fission products from the sludge and supernatants, particularly from supernatants containing high concentrations of strong chelating agents that can act to dissolve the actinides and fission products as well as interfere with subsequent metal ion extraction processes. Specifically, the fundamental understanding of chemical speciation reactions gained from these studies will help us identify other potential mechanisms (e.g., competition, displacement, or other reactions) that could be used for removing $\mathrm{Sr}$ and $\mathrm{Am} / \mathrm{Cm}$ from organic chelates present in the HLW. 


\section{Research Progress and Implications}

In fiscal year 2002, we focused our efforts on the following three areas:

1. finalizing our studies of $\mathrm{Cm}(\mathrm{III})$ speciation in the presence of the organic chelates

2. developing an accurate chemical model for the complexation of Sr with EDTA and HEDTA.

3. adding Pitzer's equations to the Environmental Simulation Program (ESP).

\section{Studies of $\mathrm{Cm}$ (III) Speciation}

In this project area, we performed fluorescence spectroscopic and lifetime measurements for $\mathrm{Cm}$ (III) solutions at approximately constant $\mathrm{Cm}$ (III) concentration $\left(8.6 \times 10^{-9} \mathrm{M}\right.$ to $\left.8.6 \times 10^{-9} \mathrm{M}\right)$ over broad concentration ranges of HEDTA $\left(2 \times 10^{-5} \mathrm{M}\right.$ to $\left.1.0 \times 10^{-1} \mathrm{M}\right)$ and $\mathrm{NaOH}\left(1.0 \times 10^{-9} \mathrm{M}\right.$ to $7.5 \mathrm{M})$. Part of the fluorescence spectra are shown in Figure 1. The spectra clearly indicate
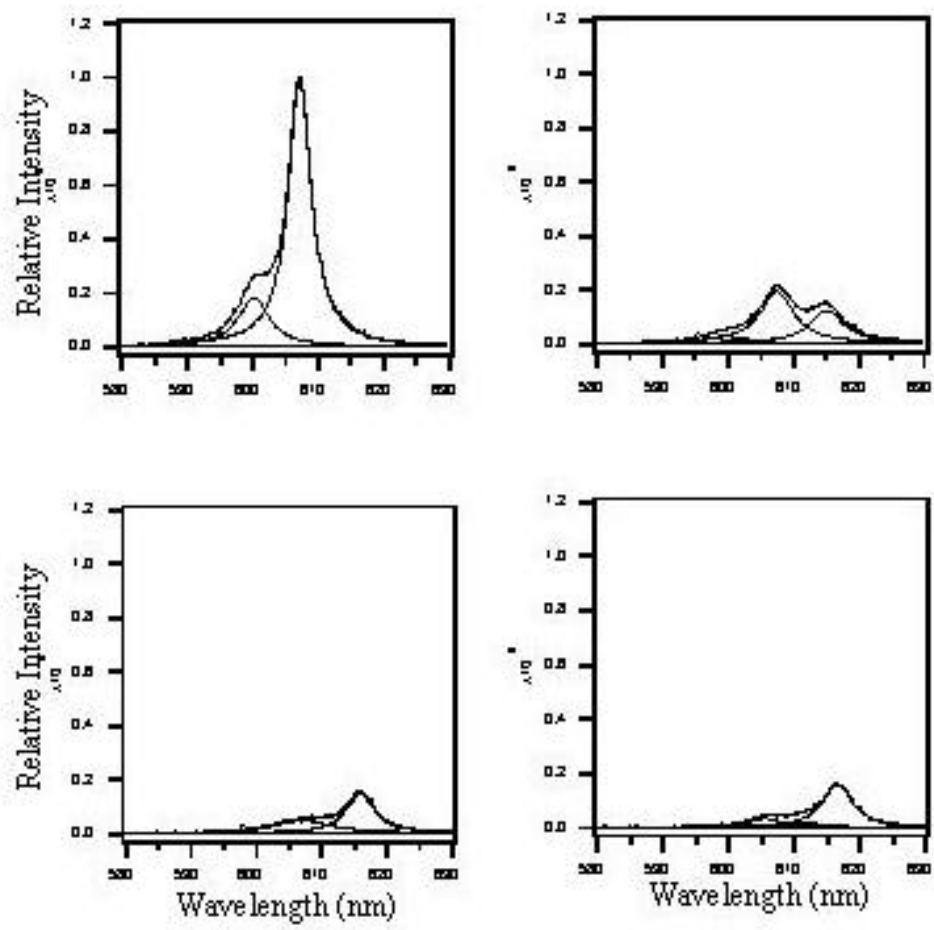

Figure 1. Fluorescence emission spectra of $\mathrm{Cm}(\mathrm{III})$ in the presence of $\mathrm{HEDTA}$ in different $\mathrm{NaOH}$ solutions. $[\mathrm{Cm}(\mathrm{III})]=9.6 \times 10^{-9} \mathrm{M}$; $[$ HEDTA $]=0.01 \mathrm{M}$; The concentrations of $\mathrm{NaOH}$ are $0.01 \mathrm{M}$ (top left); $0.50 \mathrm{M}$ (top right); $3.00 \mathrm{M}$ (bottom left); and $7.5 \mathrm{M}$ (bottom right). $\lambda_{\mathrm{ex}}=375 \mathrm{~nm}$. 
three major $\mathrm{Cm}$ (III) species with spectral maximums occurring at $600.4 \mathrm{~nm}, 607.0 \mathrm{~nm}$, and $616.0 \mathrm{~nm}$, respectively, under the test experimental conditions. The red-shift in the fluorescence spectra suggest that all three $\mathrm{Cm}$ (III) species involve inner-sphere complexation between $\mathrm{Cm}$ (III) and HEDTA. The number of water molecules calculated from the fluorescence decay constants confirm that the spectrum located at $600.4 \mathrm{~nm}$ corresponds to the 1:1 Cm-HEDTA complex, CmHEDTA, while the spectrum located at $607.0 \mathrm{~nm}$ corresponds to the 1:2 complex, $\mathrm{Cm}(\mathrm{HEDTA})_{2}{ }^{3-}$. For the third species, if a mononuclear species were assumed, there would be seven water molecules in the inner sphere of $\mathrm{Cm}(\mathrm{III})$, which is completely contradictory with the largest red-shift of the fluorescence spectra. Therefore, it is plausible to assign this species to a multi-nuclear Cm(III)-HEDTA-oxo (hydroxyl) complex. Energy transfer from excited Cm(III) ions to unexcited ions leads to a large apparent fast fluorescence decay (seemingly from more inner-sphere waters) while the strong inner-sphere complexation between Cm(III) and HEDTA is maintained. The unusually large red-shift may indicate the existence of additional covalent bonding between $\mathrm{Cm}$ (III) centers, such as those through $\mu$-oxo or hydroxyl bonding, in the molecule or cluster of molecules.

To further elucidate the nature of the third species, we prepared a series of solid suspensions containing 0.001 M HEDTA and excess solid $\mathrm{Eu}(\mathrm{OH})_{3}$ at different $\mathrm{NaOH}$ concentrations. After three days of equilibration under constant agitation, we separated the solids in the suspensions by high-speed centrifugation. After this initial separation step, we then filtered a portion of the supernatant through a filter medium with cutoff molecular weight of 40,000 Daltons. Timeresolved fluorescence spectra were recorded for the solid fraction, the supernatant, and the aqueous filtrate. The resulting spectra (partly shown in Figure 2) indicate that, for the solid fraction, characteristic $\mathrm{Eu}(\mathrm{OH})_{3}$ spectra dominate at short delay times. However, at longer delay times $(\geq 700 \mu \mathrm{s})$, the fluorescence spectra are typical of inner-sphere Eu(III)-HEDTA type complexes, which suggests that Eu(III)-HEDTA complexation probably occurred at the surface of solid $\mathrm{Eu}(\mathrm{OH})_{3}$. For the supernatant, the fluorescence spectra is again a mixture of the solid $\mathrm{Eu}(\mathrm{OH})_{3}$ and $\mathrm{Eu}(\mathrm{III})$-HEDTA complex, although the relative amount of the solid is apparently much smaller when compared to that of the solid. In the filtered supernatant, the contribution of the solid $\mathrm{Eu}(\mathrm{OH})_{3}$ was negligible. These results demonstrate that in highly basic solutions, because of the extremely small solubility product of $\mathrm{Eu}(\mathrm{OH})_{3}$ and the mono-nuclear type $\mathrm{Eu}(\mathrm{III})$ HEDTA and Eu(III)-HEDTA-OH complexes that are present, surface complexation between HEDTA and $\mathrm{Eu}(\mathrm{OH})_{3}$ colloids and clusters may also contribute to the solubility of Eu(III). The similar spectroscopic characteristics of Eu-HEDTA in excess solid $\mathrm{Eu}(\mathrm{OH})_{3}$ and $\mathrm{Cm}(\mathrm{III})$ HEDTA complexes with much lower metal concentration in concentrated $\mathrm{NaOH}$ solutions further suggest that the surface compexation between HEDTA and $\mathrm{Cm} /(\mathrm{Eu})(\mathrm{OH})_{3}$ colloids and clusters may be the dominant factor responsible for their solubility. 


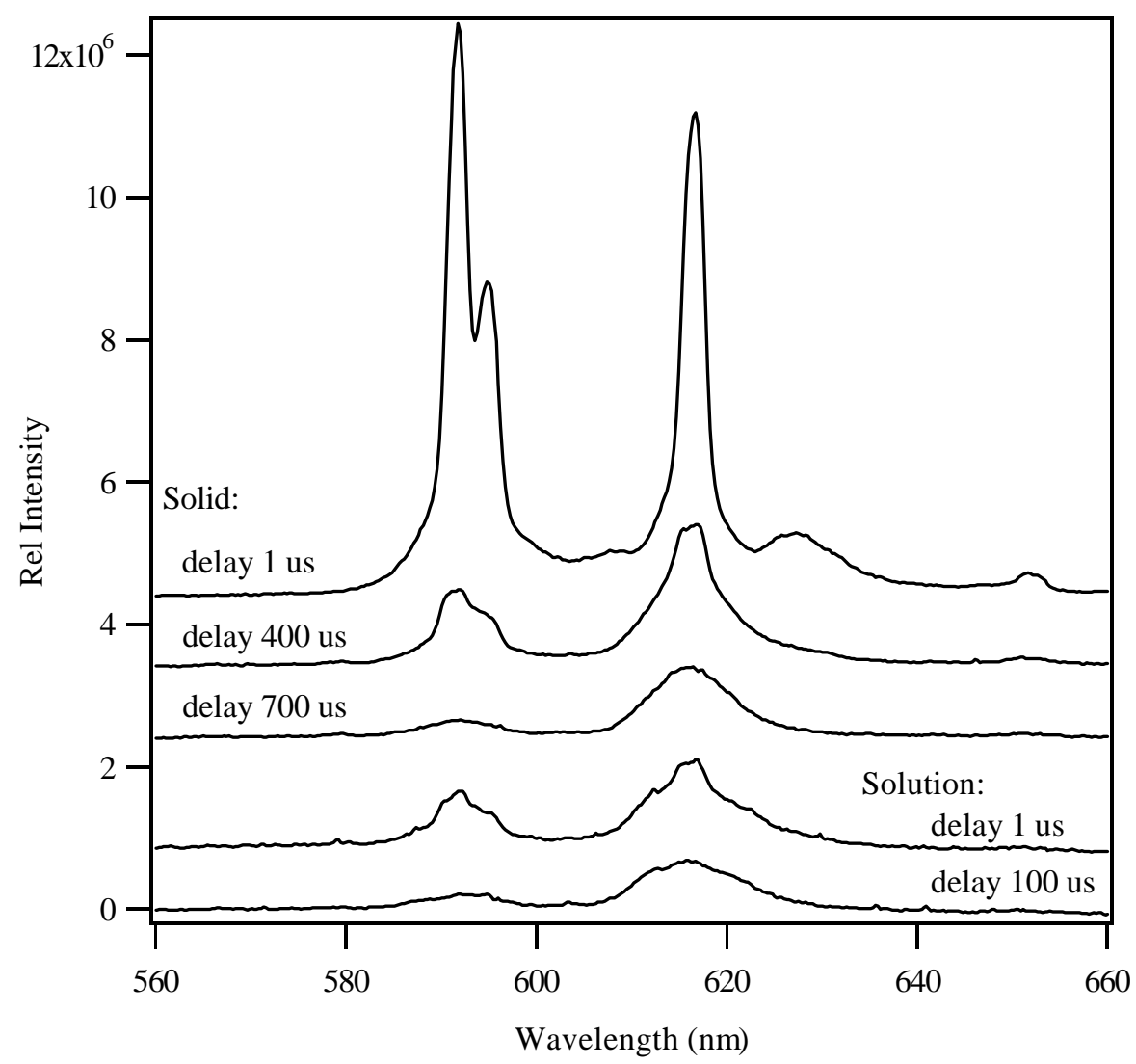

Figure 2. Time-resolved fluorescence emission spectra of $\mathrm{Eu}(\mathrm{III})$ in the presence of $0.001 \mathrm{M}$ HEDTA and excess solid $\mathrm{Eu}(\mathrm{OH})_{3}(\mathrm{~s})$ after equilibration in $7.5 \mathrm{M} \mathrm{NaOH}$ for three days. Top three spectra are for the solid and bottom two spectra are for the supernatant after high-speed centrifugation. The spectral traces are offset along the vertical axis for clarity. $\lambda_{\mathrm{ex}}=465 \mathrm{~nm}$.

\section{Studies on Strontium Speciation}

During fiscal year 2002, with partial support from the Hanford River Protection Project/Waste Treatment Plant (RPP/WTP), an aqueous thermodynamic model was developed to accurately describe the effects of $\mathrm{Na}^{+}$complexation, ionic strength, carbonate concentration, and temperature on the complexation of $\mathrm{Sr}^{2+}$ by EDTA under basic conditions. The model is based on published data of apparent equilibrium constants, enthalpies, and heat capacities and on the extensive set of solubility data on $\mathrm{SrCO}_{3}$ (c) in the presence of EDTA that we have developed during this EMSP project. The solubility data for $\mathrm{SrCO}_{3}(\mathrm{c})$ were obtained in solutions with $\mathrm{Na}_{2} \mathrm{CO}_{3}$ concentrations ranging from $0.01 \mathrm{~m}$ to $1.8 \mathrm{~m}$ and $\mathrm{NaNO}_{3}$ concentrations ranging from 0 to $5 \mathrm{~m}$, and at temperatures extending to $75^{\circ} \mathrm{C}$. The final aqueous thermodynamic model is based upon the equations of Pitzer, and it requires the inclusion of a $\mathrm{NaEDTA}^{3-}$ species as well as mixing terms between the highly charged anions $\mathrm{CO}_{3}{ }^{2-}$ and $\mathrm{NaEDTA}^{3-}$. An accurate model for the ionic strength dependence of the ion-interaction coefficients for the $\operatorname{SrEDTA}^{2-}$ and 
NaEDTA $^{3-}$ aqueous species allows the extrapolation of standard state equilibrium constants for these species, which are significantly different from the $0.1 \mathrm{~m}$ reference state values available in the literature.

These data already have been used at the Hanford site as part of the RPP/WTP.

\section{Addition of Pitzer's Equations to ESP}

During fiscal year 2002, considerable effort has been spent on incorporating new thermodynamic data (developed under EMSP and elsewhere) into the chemical processing models used at Hanford and other DOE sites. This effort resulted in the release of the "beta" version of the ESP, which includes the Pitzer equations, at the Hanford and Savannah River sites. This enhanced capability will allow all of the new thermodynamic data developed under EMSP to be used by the site contractors.

\section{Planned Activities}

In fiscal year 2003, we plan to finalize our studies of the effects of base concentration on the organic chelates and strontium species. In addition, we will study the effects of metal ions that can compete with the trivalent actinides and $\mathrm{Sr}$ for the chelates. These efforts will focus on $\mathrm{Ni}$, which forms some of the strongest aqueous complexes known with EDTA under highly basic conditions.

\section{Information Access}

\section{Publications and Presentations (FY02 only)}

Felmy AR, H Cho, GR Choppin, DA Dixon, GT MacLean, JR Rustad, Z Wang, and X Xia. 2001. Development of Accurate Chemical Models for Tank Applications: Coupling Engineering Application with Good Science. Lunch hour presentation as an example of a successful EMSP Program, EMSP Tanks Focus Area (TFA) Workshop, November 7-8, 2001, Richland, Washington.

Felmy AR 2001. Thermodynamic Modeling and Equilibrium Data. Presentation to the RPP-WTP Review Panels, October 31, 2001, Richland, Washington.

Wang Z, X Xia, MJ Mason, and AR Felmy. 2001. Investigations of Cm(III) Speciation in Strongly Basic Solutions by Time Resolved Laser Fluoresence Spectroscopy. $222^{\text {nd }}$ ACS National Meeting, August 26-30, Chicago Illinois. 
Sanders S, R Young, and AR Felmy. 2001. Inclusion of Pitzer Equations in the ESP Computer Model (Beta Version). Tanks Focus Area Milestone Report B.3-1 (September 2001).

Felmy AR and GT MacLean. 2001. Development of an Enhanced Database for the ESP Model: The Fluoride and Phosphate Components. WTP-RPT-018 Rev. 0. Prepared for Bechtel National Inc. by Pacific Northwest National Laboratory, Richland, Washington.

Felmy AR and P McKenzie. 2002. Incorporation of Pitzer Parameters in ESP. TFA Salt Cake Dissolution and Waste Chemistry Workshop, May 14-16, 2002, Richland, Washington.

Felmy AR 2002. Thermodynamic Modeling and Equilibrium Data. Presentation to the RPP-WTP Review Panels, April 2002, Richland, Washington.

\section{Other Contributions}

In addition to the previously described scientific contributions, the principal investigators on this project also worked to enhance the overall success of the EMSP program. Specific examples of these activities are described below.

A.R. Felmy (PNNL) was a co-organizer of the "Accomplishment of the Environmental Management Sciences Program (EMSP) Symposium" at the $222^{\text {nd }}$ ACS National Meeting held in Chicago, Illinois on August 26-30, 2001. The symposium consisted of five different sessions covering the areas of subsurface science, solution and tank chemistry, radionuclide and contaminant separation methods, analytical and sensing techniques, and waste form treatment and development. There were 65 oral or poster presentations in the symposium.

G.R. Choppin (FSU) serves as a member of the EMSP Advisory Committee and the NAS/NRC Board of Radioactive Waste Management. 